\title{
Re-HEDP : pharmacokinetic characterization, clinical and dosimetric evaluation in osseous metastatic patients with two levels of radiopharmaceutical dose Eduardo Savio*1, Javier Gaudiano², Ana M Robles3, Henia Balter3, Andrea Paolino ${ }^{1}$, Andrea López3, Juan C Hermida², Eugenia De Marco ${ }^{2}$, Graciela Martinez ${ }^{2}$, Eduardo Osinaga 4 and Furn F Knapp Jr5
}

\author{
Address: ${ }^{1}$ Cátedra de Radioquímica, Facultad de Química, Uruguay, ${ }^{2}$ Centro de Medicina Nuclear, Hospital de Clínicas, Facultad de Medicina, \\ Uruguay, 3Centro de Investigaciones Nucleares, Facultad de Ciencias, Uruguay, 4Laboratorio de Oncologia Básica y Biología Molecular, \\ Facultad de Medicina Universidad de la República, Montevideo, Uruguay and 5Oak Ridge National Laboratory, Nuclear Medicine Group, USA \\ E-mail: Eduardo Savio* - esavio@bilbo.edu.uy; Javier Gaudiano - gaudiano@hc.edu.uy; Ana M Robles - anamar@cin1.cin.edu.uy; \\ Henia Balter - jbalter@cin.edu.uy; Andrea Paolino - apaolino@hotmail.com; Andrea López - alharksen@hotmail.com; \\ Juan C Hermida - juchermi@adinet.com.uy; Eugenia De Marco - radguim@bilbo.edu.uy; Graciela Martinez - radguim@bilbo.edu.uy; \\ Eduardo Osinaga - eosinaga@lobbm.fmed.edu.uy; Furn F Knapp - jkp@ornl.gov \\ ${ }^{*}$ Corresponding author
}

Published: 21 November 200I

BMC Nuclear Medicine 200I, I:2
Received: 9 August 2001

Accepted: 21 November 2001

This article is available from: http://www.biomedcentral.com/I47I-2385/I/2

(C) 200I Savio et al; licensee BioMed Central Ltd. Verbatim copying and redistribution of this article are permitted in any medium for any non-commercial purpose, provided this notice is preserved along with the article's original URL. For commercial use, contact info@biomedcentral.com

\begin{abstract}
Background: A study for pain relief therapy with ${ }^{188}$ Re-HEDP was done in patients with bone metastases secondary to breast and prostate cancer.

Materials and Methods: Patients received I.3 or $2.2 \mathrm{GBq}$, in single or multiple doses. Platelets, white and red cells were evaluated during II weeks. Pharmacokinetic characterization was done from blood and urine samples for 5 patients along 24 hours. Urinary excretion was evaluated in other 16 patients during 6 hours. Bone uptake was estimated as remaining activity in whole body. Scintigraphic images were acquired at 2 and 24 hs post-administration. Absorbed dose in bone marrow was estimated with Mirdose3. Analgesics intake and pain score were daily recorded. Tumour markers (PSA, and Tn-structure) were monitored in 9 patients during 4 to 6 months. Single doses of low activity ( $1.3 \mathrm{GBq})$ were given to twelve patients. Nine patients received multiple doses.

Results: All except one patient had normal levels of platelets, white and red cells. Remaining dose in blood at 2 hours was $9 \%$. Urinary elimination was $58 \%$. Bone uptake at 24 hours was $43 \%$ (mean value; $n=5$ ). No changes of the haematological parameters were detected along follow-up period. Pain relief was evidenced by decrease or supression of opioid analgesic and by subjective index. PSA showed a decrease in prostate cancer patients $(n=4)$. Tn-structure showed a significant increase after 4 to 8 months.
\end{abstract}

Conclusion: Single or multiple dose scheme could be safely used, with administered activity of ${ }^{188} \mathrm{Re}-\mathrm{HEDP}$ up to $60 \mathrm{mCi}$, with low bone marrow absorbed doses.

\section{Background}

Cancer is the second more frequent cause of death, after cardiovascular disease in developed countries. Most of adult patients with neoplasms will develop skeletal metastases that can lead to progressive pain. The development of less toxic but equally effective pain relieving 
agents for bone metastases has been a field of increasing interest to nuclear medicine [1-6]. In that sense, the application of bone-seeking radiopharmaceuticals is a promising alternative for hemi-body or whole-body radiotherapy.

After the successful application of $32 \mathrm{P}$ and $89 \mathrm{Sr}$ [7-9], new $\beta^{-}$emitter phosphonate radiopharmaceuticals were developed.

In particular ${ }^{186} \mathrm{Re}(\mathrm{Sn})$ hydroxyethylidene bisphosphonate (HEDP) and 153Sm ethylenediaminetetramethylenephosphonic acid (EDTMP) have shown favourable biodistributions and dosimetries, having thus been approved for clinical use [10-15]. As ${ }^{186} \mathrm{Re}$ and $153 \mathrm{Sm}$, ${ }_{188}$ Re emits both beta particles suitable for therapy and a gamma ray ( $155 \mathrm{keV})$, adequate for diagnostic imaging in order to verify localisation in the pain areas associated to metastatic process [16-22]. Besides, ${ }^{188}$ Re may be obtained from a ${ }^{188}$ Tungsten/188Rhenium generator, resulting in a readily available system for a daily elution [23-26].

Scintigraphy is the most useful and widely documented diagnostic tool for detection of bone metastases. It is directly related to turnover of biochemical markers such as prostatic acid phosphatase (PAP) and deoxypyrrolidine (DPD) in urine. Besides, in early stages after administration of phosphonate radiopharmaceuticals it is not advisable to use bone turnover markers. Thus, scintigraphic evaluation of local action of $\beta$ radiation in metastatic tissue plays an important role.

Characterisation of pharmacokinetic behaviour of 188Rhenium-(Sn)-HEDP carried out in a limited number of patients $(n=5)$ was applied in the assessment of safety and therapeutic efficacy of the treatment of painful osseous metastases under two levels of administered dose (35 and $60 \mathrm{mCi} ; 1.3$ and $2.2 \mathrm{GBq}$ ) of this radiopharmaceutical.

Analgesics intake along a period of time after radiopharmaceutical administration, following a recorded self estimation by the patient associated to scored physical activities, is a current procedure for evaluation of osseous pain relief [27].

Tumour markers have been determined in a group of 9 patients, being Tn structure evaluated in all of them due to its broad specificity spectrum, while PSA and free PSA only in those with prostate cancer.

Alterations in carbohydrate profile at cell surface have been proved in almost all types of cancer [28] influencing cellular growth [29], invasiveness [30] and metastatic potential. Monoclonal antibody 83D4 [31] recognizes specifically the carbohydrate antigen Tn (N acetylgalactosamine O-serine/threonine) expressed in more than 90\% of ovaries, endometrium and breast cancers but not in normal tissues or blood cells [32]. Prostatic specific antigen (PSA) is secreted by prostate cells into seminal fluid. Serum levels of total PSA are aberrantly increased in prostate cancer patients [33], having a very high sensitivity ( $>85 \%)$ and specificity ( $>90 \%$ ) as a marker for that disease.

Single and multiple doses of ${ }^{188}$ Re-HEDP-both containing low (35 mCi, 1.3 GBq) and high $(60 \mathrm{mCi}, 2.2 \mathrm{GBq})$ levels of activity doses - were given to a population of 21 patients to assess the possibility of using this scheme safely and reliably, evaluating haematological follow up, absorbed dose in bone marrow, tumour markers and analgesic intake.

\section{Materials and methods \\ Materials \\ Equipment and software}

Capintec CRC-12 dose calibrator (CII, USA) was used with a calibration factor fixed at $496(\times 10)$. Radioactivity measurements of chromatographies, blood samples, plasma and protein precipitate were performed in a NaI (Tl) Mini Assay Type G-20 gamma counter (Picker, USA). Scintigraphic images were acquired in a Sophycammera DSX, 93 PMT, SPECT (SOPHA, France). Multiple regression analysis (MRA) and data processing by Reglin program [34] was applied for model fitting, as well as Mirdose3 for dosimetry purposes [35]. Radioactivity measurements of 125Iodine (0.01 kBq-111 kBq) were done in an automatic well-type gamma counter (Compact-120 Picker, USA) with a coaxial NaI (Tl) detector and efficiency of $70 \%$.

\section{Radiopharmaceutical}

${ }^{188}$ Re-HEDP (radiochemical purity $>98 \%$ ) has been prepared from lyophilised and locally produced kits [36] using ${ }^{188} \mathrm{Re}$ eluted from a ${ }^{188 \mathrm{~W} / 188}$ Re generator $[25,26]$. Radiochemical purity was determined by ascending chromatography with acetone and $\mathrm{NaCl} 0.9 \%$ as mobile phases and Whatman $1 \mathrm{M}$ and $3 \mathrm{M}$ as stationary phases respectively.

\section{Protocol}

Patients were selected according to the protocol approved by the Ethical Committee of the University Hospital, Faculty of Medicine, Montevideo, Uruguay. The criteria for admission of patients to the study were: bone metastases in patient with cancer; failure of prior conventional therapy (i.e. prostate cancer patients resistant to therapy with hormones); multiple metastases in bone scanning, white cells and platelets number higher than 
Table I: Patient clinical characteristic.

\begin{tabular}{|c|c|c|c|}
\hline Patient & Age (years) & Sex & Cancer \\
\hline I & 70 & $M$ & Prostate \\
\hline 2 & 76 & $M$ & Prostate \\
\hline 3 & 56 & $M$ & Prostate \\
\hline 4 & 68 & $M$ & Prostate \\
\hline 5 & 65 & $M$ & Prostate \\
\hline 6 & 74 & $M$ & Prostate \\
\hline 7 & 61 & $M$ & Prostate \\
\hline 8 & 65 & $M$ & Prostate \\
\hline 9 & 66 & $\mathrm{~F}$ & Breast \\
\hline 10 & 34 & $\mathrm{~F}$ & Breast \\
\hline 11 & 42 & $\mathrm{~F}$ & Cervix \\
\hline 12 & 51 & $\mathrm{~F}$ & Breast \\
\hline 13 & 69 & $\mathrm{~F}$ & Breast \\
\hline 14 & 72 & $M$ & Unknown primitive cancer \\
\hline 15 & 64 & $\mathrm{~F}$ & Breast \\
\hline 16 & 62 & $M$ & Prostate \\
\hline 17 & 62 & $M$ & Prostate \\
\hline 18 & 74 & $M$ & Medullar Thyroid \\
\hline 19 & 54 & $M$ & Prostate \\
\hline 20 & 77 & $\mathrm{~F}$ & Breast \\
\hline 21 & 50 & $\mathrm{~F}$ & Breast \\
\hline
\end{tabular}

mean value \pm standard deviation $=62 \pm \mathrm{II}$ years

$4000 / \mathrm{mm}^{3}\left(4 \times 10^{9} /\right.$ litre $)$ and $150.000 / \mathrm{mm}^{3}\left(100 \times 10^{9} /\right.$ litre) respectively; serum creatinine concentration less or equal to $1.5 \mathrm{mg} / \mathrm{dL}$ (133 $\mu$ mole/litre). On the other hand, exclusion criteria were: obstructive renal pathology or renal insufficiency; urinary incontinence; psychiatric pathology; evidence of spinal marrow compression; pathological fracture.

\section{Population}

Two groups integrated by a total number of twenty-one patients with painful bone metastases (age: $62 \pm 11$ years; 13 male and 8 female) were studied after they had provided written informed consent. Table 1 describes primary cancer for each patient: prostate $(\mathrm{n}=11)$, breast $(\mathrm{n}=$ 7), cervix ( $n=1)$, medullar of the thyroid $(n=1)$ and unknown primitive $(n=1)$. Five of them, who were treated with radiotherapy which had turned ineffective, participated in the pharmacokinetic characterisation of the radiopharmaceutical Two patients had a platelet number less than $150.000 / \mathrm{mm}^{3}$ and short life expectancy.

\section{Methodology}

Group I $(\mathrm{n}=12)$ received an intravenous tracer dose followed by a therapeutic dose 24 hours later, both administered as a bolus $(1-2 \mathrm{~mL})$. The maximum accumulated dose was set at $35 \mathrm{mCi}(1295 \mathrm{MBq})$, considering radia- tion safety as well as reasonable expectancy of therapeutic benefit.

The second group ( $\mathrm{n}=9$, Group II) participated in a scaled dose protocol with a proposed dose of $60 \mathrm{mCi}$ (2220 MBq) for a $40 \%$ bone uptake.

Five patients from Group I, who participated of pharmacokinetic characterisation of the radiopharmaceutical, were hospitalised and remained 24 hours after therapeutic dose administration for control and sample collection. Pre-hydration was not performed.

Image acquisition

Scintigraphic images were acquired immediately and 24 hs after first dose administration. Lesion to normal bone ratio was determined in selected metastases.

\section{Blood sampling and urine collection}

Blood samples were drawn from an antecubital vein opposite to the injection site at preset intervals $(2,4,8,12$, 30 min, and 1, 2, 4, 6, 12 and 24 hs post-injection) with heparinised syringes in the 5 patients of Group I, subject to pharmacokinetic characterisation. Also total urine was collected at time intervals $(0-1,1-2,2-4,4-6,6-12$, $12-18$ and $18-24$ hours). In the other group $(n=16)$ only urine collection until 6 hours (0-1, 1-2, 2-4, 4-6 hs) was performed and 24 hours excretion was estimated. Catheterization was done to facilitate sample collection and minimize possible contamination, as well as to diminish bladder wall irradiation due to urinary retention.

Blood analysis for compartmental distribution of radiopharmaceutical

A volume of $1 \mathrm{~mL}$ of blood was measured for total activity. Plasma was separated by centrifugation. Trichloroacetic acid (TCA) for protein precipitation was added to plasma and centrifuged during 5 minutes. Measurements of activity present in blood, plasma, TCA supernatant and precipitate were done.

Table 2: Protein binding values

Time (h) mean value \pm s.d.

$\begin{array}{ll}0.08 & 44 \pm 12 \\ 0.60 & 46 \pm 12 \\ 1.00 & 48 \pm 12 \\ 2.00 & 53 \pm 14 \\ 6.00 & 62 \pm 12 \\ 12.0 & 69 \pm 11\end{array}$


Table 3: Phases constants in a three compartment model for 188Re-HEDP for blood and plasma samples.

\begin{tabular}{ccc}
\hline Phase constant & Blood $^{*}(\mathrm{~h})$ & Plasma $^{*}(\mathrm{~h})$ \\
\hline & & \\
$\alpha$ & $0.14 \pm 0.16$ & $0.12 \pm 0.11$ \\
$\beta$ & $1.5 \pm 0.7$ & $1.3 \pm 0.8$ \\
& $15 \pm 8$ & $21 \pm 8$ \\
\hline
\end{tabular}

* mean value \pm standard deviation, $\mathrm{n}=5$

\section{Urine excretion}

Total recovered volume of urine was measured and aliquots of $20 \mathrm{~mL}$ were assayed for radioactivity in dose calibrator. Suitable corrections were introduced for physical decay.

Data processing and pharmacokinetics modelling Whole blood volume was estimated on the basis of patient weight and height.

Multiple regression analysis of blood and plasma profiles was performed. Calculation of microconstants $(\pi, \alpha, \beta)$ were obtained by model fitting (Table 23) [37].

Elimination constant $\left(\mathrm{k}_{\mathrm{e}}\right)$ was calculated from urine profiles by:

$\ln \left(1-E / A_{O}\right)=-k_{O} t$, where $E$ is urine activity at time $t$ and $\mathrm{A}_{\mathrm{O}}$ is the administered dose. Bone uptake was estimated as remaining dose at 24 hours, by $A_{O}-E_{\max }$, where $A_{O}$ is the ${ }^{188}$ Re-HEDP administered dose and $\mathrm{E}_{\text {max }}$ is total accumulated urine excretion.

\section{Haematological follow-up}

Number of platelets and white and red cells were weekly controlled during 11 weeks.

\section{Tumour markers}

Prostatic specific antigen (PSA) was evaluated in 6 male patients, 5 with prostate cancer and one with thyroid cancer. Tn structure was evaluated in 8 patients: prostate cancer $(n=5)$, breast cancer $(n=2)$, thyroid cancer $(n=1)$.

PSA determination was done with locally produced immunoradiometric assay (IRMA) consisting in two monoclonal antibodies, specific for the exposed epitope of the PSA molecule, one as capture antibody and the other as tracer upon labelling with $125 \mathrm{I}$ by limiting chloramine-T method [38].
Tn structure was evaluated by an homologous IRMA assay locally produced using a specific antibody 83D4 of the type IgM immobilised to a solid phase. As standard a Tn-rich mucin was used and the complex was detected by means of the $83 \mathrm{D} 4$ labelled with $125 \mathrm{I}$.

\section{Therapeutic response evaluation}

Patients were given a form for daily self-evaluation and record of pain (scaled between o and 5), physical activity and analgesic administration (amount and kind of drug).

Dosimetry

Residence time in trabecular bone was considered equal to that in cortical bone, and calculated as follow:

Residence time $=(0.5 \times \mathrm{C} / \mathrm{A} \times 1.443 \times 16.9) \mathrm{h}$

C - Bone uptake (mCi)

A - Dose administered (mCi)

$16.9-t_{1 / 2}$ of $188 \mathrm{Re}$

Dose absorbed to bone marrow was calculated using Mirdose Version 3.0, introducing residence time values calculated as described above.

\section{Results}

${ }^{188}$ Re-HEDP was labelled with a radiochemical purity higher than $99 \%$ and showed an in-vivo profile similar to 99mTc-HEDP, with a clearance of $70 \%$ within the first 6 hours and a bone uptake of 10 to $70 \%$.

Figure 1 shows a typical blood and plasma activity concentration profile for one patient, following the thera-

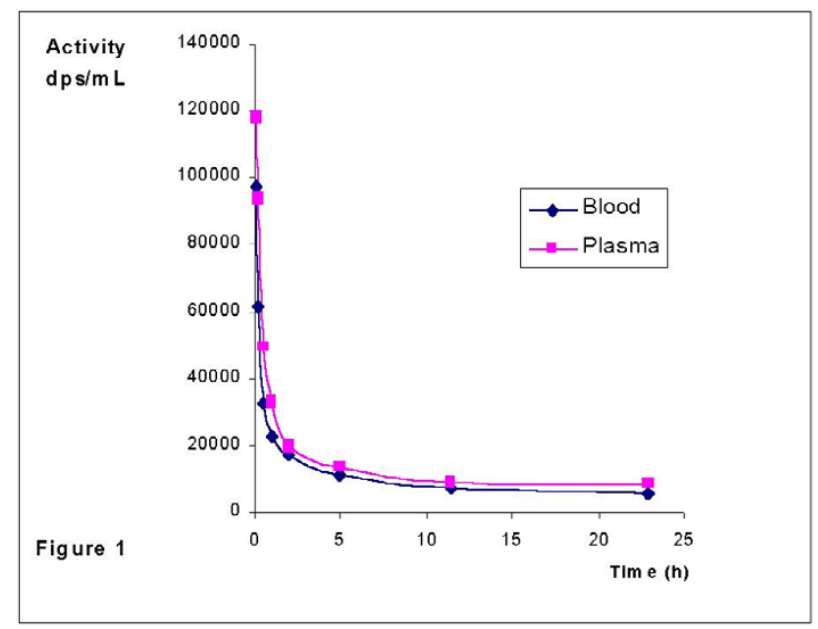

Figure I

Blood and plasma profiles after ${ }^{188}$ Re-HEDP administration 


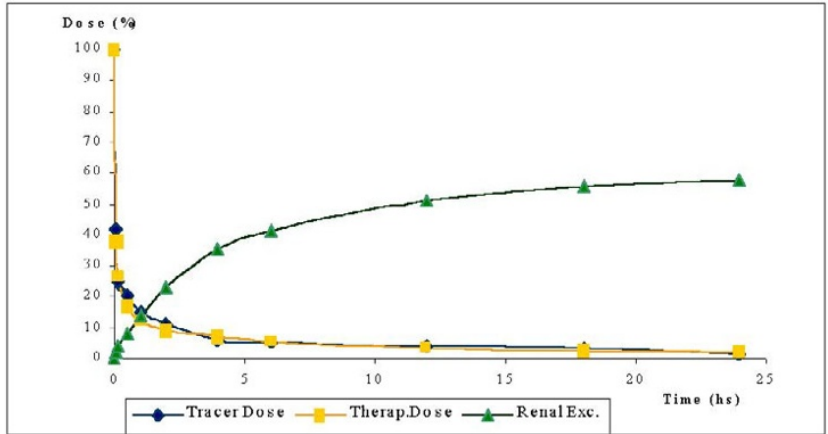

Figure 2

Blood clearance (after tracer and therapeutic dose) and renal excretion for a group of five patients, who were administered $35 \mathrm{mCi}(1295 \mathrm{MBq})$ of ${ }^{88} \mathrm{Re}-\mathrm{HEDP}$

peutic dose. Radiopharmaceutical binding to blood cells was less than $8 \%$.

Protein binding at five minutes after administration was (44 \pm 12 )\%, while $26 \%$ of the injected dose (I.D.) remained in blood, and increased to $(69 \pm 11) \%$ at twelve hours ( $3 \%$ of the I.D. remained in blood), as it is shown in Table 32. In one patient whose hematocrit value was below $20 \%$, protein binding percentage was initially $75 \%$ ( $38 \%$ of the I.D.) and raised to almost $90 \%$ at twelve hours ( $2 \%$ of the I.D.). This fact was also previously reported for ${ }^{186}$ Re-HEDP, attributing to a possible in vivo decomposition leading to compounds having a different plasma protein binding [22].

Figure 2 shows the blood clearance as a function of time (percentage of remaining dose of tracer and therapeutic administrations) and accumulated excreted urine as percentage of administered dose versus time. No statistical differences were observed between both administrations. Similar blood clearances are observed for both dose administrations. A three compartment model was the best fit for the five patients and the corresponding half-lives to each phase are shown in Table 23. A disposition phase $(\pi)$ that took place during the first $30 \mathrm{~min}$ utes post administration was verified, followed by a disposition phase $(\alpha)$ calculated from $(17 \pm 4) \%$ to $(9 \pm$ $2) \%$ of the I.D. (between 30 minutes and 2 hours). Finally, the elimination phase $(\beta)$ took place from $(5 \pm 1) \%$ to $(2 \pm 1) \%$ of the I.D., estimated from 6 to 24 hours postadministration curve.
Urine profile showed that $(58 \pm 15) \%$ of I.D. was eliminated in 24 hours, being its $70 \%$ collected along the first 6 hours post-administration. Table 4 shows renal elimination $\left(t_{1 / 2}\right)$ for these patients.

Table 5 shows bone uptake, bone marrow dose per activity unit administered (corrected to a weight of $70 \mathrm{~kg}$ ) and total bone marrow dose are represented in Table 5, after single or multiple ${ }^{188}$ Re-HEDP administration (Group I and II). A great variability in bone uptake was verified ( $44 \pm 18 \%$ in Group I; $31 \pm 18 \%$ in Group II). Nevertheless, maximum total absorbed dose to bone marrow was similar for both groups, having received a mean value of 31 or $55 \mathrm{mCi}$ (1147 or $2035 \mathrm{MBq}$ ). On the other hand, while all the patients received $0.29-1.18 \mathrm{mCi} / \mathrm{kg}(10.7-$ $43.7 \mathrm{MBq} / \mathrm{kg}$ ), dosimetry estimations showed that higher bone uptake correlated with higher absorbed doses to bone marrow. Biochemical parameters (number of platelets, white and red cells variation during a time interval of 11 or 24 weeks (single or multiple dose) are shown in Figure 3, for representative patients of each
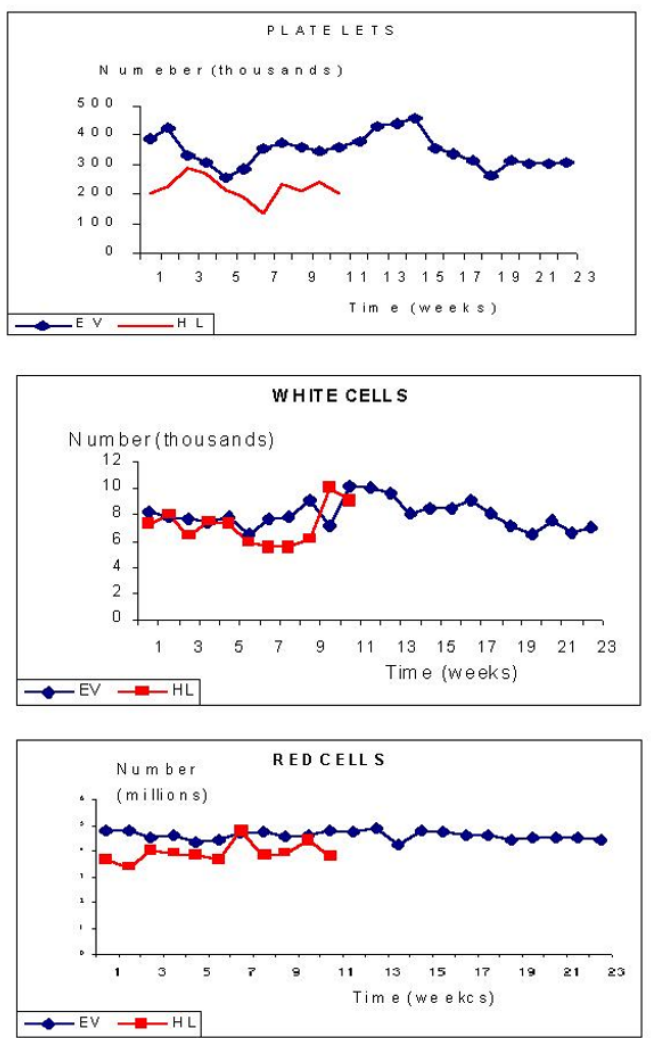

\section{Figure 3}

Haematological parameters in two patients who received 35 or $60 \mathrm{mCi}$ (I295 or $2220 \mathrm{MBq}$ ) of 188Re-HEDP (single and multiple dose respectively) vs. time 
Table 4: Renal elimination $t_{1 / 2}$ after therapeutic dose administration.

\begin{tabular}{cc}
\hline Patient & $\mathrm{t}_{1 / 2}(\mathrm{hrs})$ \\
& \\
$\mathrm{AP}$ & 10.5 \\
$\mathrm{HL}$ & 5.1 \\
$\mathrm{FC}$ & 9.1 \\
$\mathrm{NR}$ & 7.3 \\
TD & 5.0 \\
mean value \pm s.d. & $4.4 \pm 3.5$ \\
\end{tabular}

group (patient 8 - Group I and patient 17 - Group II). Only two patients, whose initial platelet number was lower than recommended by the acceptance limit, showed a significant decrease respect the others. The overall platelet decrease found in the fourth week after dose administration, which correspond to the minimum values, was of $(18 \pm 3) \%$ in Group I and $(29 \pm 4) \%$ in Group II, being the difference between both groups statistically significant $(\mathrm{p}<0.001)$. No variations of red and white cells were observed because of ${ }^{188}$ Re-HEDP treatment.

Pain evaluation, measured by subjective index for 18 patients, is shown in Table 6. Seventy eight per cent of these patients $(n=14)$ recognized a decrease of $60 \%$ of the initial pain, compared to the status previous to receiving the therapeutic dose of 188 Re-HEDP. Two patients (11\%) experimented a pain increase and another two found no change. A decrease of $62 \%$ is reported in analgesic drug treatment for 14 cases (78\%); it remained as before ${ }^{188}$ Re-HEDP treatment in 3 patients (17\%) and was increased in one of them (5\%).

Opiates were used in 14 patients (78\%); intake was decreased in 8 patients (57\%) and totally abandoned in the rest.

In those patients who referred an initial good pain relief, a second dose was administered with an elapsed time of three to four months from the first one. Dosimetric evaluation (see Table 5) also showed a safe profile protocol. Three doses were administered to only one patient, with a good quality of life.

With reference to tumour markers, four patients presented increased PSA serum levels (140 $\pm 23 \mathrm{ng} / \mathrm{mL})$ previous to the first $188 \mathrm{Re}-\mathrm{HEDP}$ administration, one patient showed a slightly high level $(7.2 \mathrm{ng} / \mathrm{mL})$ and one patient (thyroid disease) was in the normal range (1.4 $\mathrm{ng} / \mathrm{mL}$ ). The follow-up showed that the four patients with PSA initially high, lowered their values in a ratio of $2.3 \pm 0.7$ respect to first determinations. In the second situation, there was no decrease in serum values, which remained in $15.5 \pm 3 \mathrm{ng} / \mathrm{mL}$ during almost 4 months after administration of radiopharmaceutical. The patient, in the normal range, remained unchanged with a mean value of $1.5 \pm 0.5 \mathrm{ng} / \mathrm{mL}$ during 8 months.

About Tn structure, initial values were low in 7 patients $(3 \pm 2 \mathrm{ng} / \mathrm{mL})$ and very elevated in one breast cancer $(74$ $\mathrm{ng} / \mathrm{mL}$ ). The follow-up of patients with initial low Tn values showed an increase of more than $54 \mathrm{ng} / \mathrm{mL}$, which appeared after 4 to 8 months of administration of first treatment.

\section{Discussion}

${ }^{188}$ Re-HEDP was labelled with a radiochemical purity higher than $99 \%$ and showed an in-vivo profile similar to $99 \mathrm{mTc}-\mathrm{HEDP}$, with a fast clearance and a high variability in bone uptake.

Blood clearance profiles were also similar to those reported for 99mTc-HEDP [39], except for long times where higher values were determined for ${ }^{188}$ Re-HEDP ( $5 \%$ of I.D. after 12 hs post-administration).

The clinical results included evaluation of radiopharmaceutical toxicity that could be evidenced by the variation in haematological parameters (platelet, white and red blood cell count) and changes in pain and drug intake. All of these were measurable parameters, except changes in pain which were subjectively appreciated by the patients themselves. The chosen approach of self-assessment by a conventional scale was adequate, providing a reasonable understanding of the situation by the patients.

Haematological evaluation showed that platelets were the most sensitive element. A decrease in the number of platelets was observed in every dose. Nevertheless, only two patients arrived to an abnormal platelet count, and these were patients whose former blood element count was out of the admission parameters and were given a dose because it was the only pain relief alternative that could be offered. In spite of the low platelet count, no bleeding were evident and it was verified a clear pain relief. Overall decrease of platelet counting, even in the more pronounced cases, remained in levels that did not affect the evolution of the patient. Patients receiving higher doses (Group II) were affected by a more pronounced decrease in platelet counting respect to the lower dose group (Group I).

With reference to white cell counting the decrease observed in the first period (four weeks) was recovered by 
Table 5: Dosimetric estimations for absorbed doses after single or multiple ${ }^{188}$ Re-HEDP administration, with two levels of activity

\begin{tabular}{|c|c|c|c|c|c|c|c|c|c|}
\hline & Patient & $\begin{array}{c}\text { Adm. Dose } \\
\mathrm{mCi}\end{array}$ & $\begin{array}{c}\text { Weight } \\
\mathrm{kg}\end{array}$ & $\begin{array}{c}\text { Adm.Dose } / \mathrm{kg} \\
\mathrm{kg}\end{array}$ & $\begin{array}{c}\text { Bone Uptake } \\
\text { (\%) }\end{array}$ & $\begin{array}{l}\text { Res.Time } \\
\text { hrs }\end{array}$ & $\begin{array}{l}\text { B.M.D. } \\
\mathrm{rad} / \mathrm{mCi}\end{array}$ & $\begin{array}{c}\text { TBMD } \\
\mathrm{rad}\end{array}$ & $\begin{array}{c}\mathrm{TBMD} / \mathrm{w} \\
\mathrm{rad}\end{array}$ \\
\hline \multicolumn{10}{|c|}{ Group I } \\
\hline I & L.H. & 41,6 & 88,2 & 0,47 & 59 & 7,2 & 3,04 & 126,46 & 159,3 \\
\hline 2 & G.M & 35,3 & 61 & 0,58 & 68,7 & 8,4 & 3,54 & 124,96 & 108,9 \\
\hline 3 & A.P & 33,09 & 75 & 0,44 & 65,4 & 8 & 3,38 & || $\mid, 84$ & 119,8 \\
\hline 4 & J.P. & 34,8 & 80 & 0,44 & 43,5 & 5,3 & 2,24 & 77,95 & 89,1 \\
\hline 5 & E.S & 30,7 & 62 & 0,5 & 63,6 & 7,8 & 3,29 & 101 & 89,5 \\
\hline 6 & F.C & 30,7 & 67 & 0,46 & 43,7 & 5,3 & 2,24 & 68,77 & 65,8 \\
\hline 7 & S.V. & 24,4 & 83 & 0,29 & 46,9 & 5,7 & 2,4 & 58,56 & 69,4 \\
\hline 8 & H.L & 26,7 & 68 & 0,39 & 39,6 & 4,8 & 2,03 & 54,2 & 52,7 \\
\hline 9 & N.R & 25,5 & 62 & $0,4 I$ & 38,5 & 4,7 & 1,98 & 50,49 & 44,7 \\
\hline 10 & G.F & 27,5 & 57 & 0,48 & 25,2 & 3,1 & $|, 3|$ & 36,03 & 29,3 \\
\hline 11 & T.D. & 19,4 & 65,5 & 0,3 & 25,3 & 3,1 & $|, 3|$ & $25,4 I$ & 23,8 \\
\hline 12 & B.B. & 38,7 & 92 & 0,42 & 10,1 & 1,2 & 0,51 & 19,74 & 25,9 \\
\hline mean & & 31 & 72 & 0,43 & 44 & 5,4 & 2,3 & 71 & 73 \\
\hline s.d. & & 6 & 12 & 0,08 & 18 & 2,2 & 0,9 & 37 & 42 \\
\hline
\end{tabular}

Group II

\begin{tabular}{|c|c|c|c|c|c|c|c|c|c|}
\hline 13 & D.R. & 65,9 & 77 & 0,86 & 33,4 & 4,1 & 1,73 & || $4,0 \mid$ & 124,8 \\
\hline 14 & APC & 60 & 60 & 1 & 41,2 & 5 & 2,11 & 126,6 & 108,5 \\
\hline \multirow[t]{2}{*}{15} & M.M & 38,3 & 62 & 0,62 & 36,6 & 4,5 & 1,9 & 72,77 & 64,5 \\
\hline & M.M & 27 & 62 & 0,44 & 47,1 & 5,7 & 2,4 & 64,8 & 57,4 \\
\hline \multirow[t]{2}{*}{16} & J.F. & 64,7 & 86 & 0,75 & 27,7 & 3,4 & 1,43 & 92,52 & 113,7 \\
\hline & J.F. & 63 & 85 & 0,74 & 55,1 & 6,7 & 2,83 & 178,29 & 216,5 \\
\hline \multirow[t]{2}{*}{17} & E.V. & 42,5 & 93 & 0,46 & 39,8 & 4,9 & 2,07 & 87,98 & 116,9 \\
\hline & E.V. & 72,9 & 92 & 0,79 & 12,6 & 1,5 & 0,63 & 45,93 & 60,4 \\
\hline \multirow[t]{2}{*}{18} & C.B. & 76,8 & 68 & 1,13 & 15,5 & 1,9 & 0,8 & 61,44 & 59,7 \\
\hline & C.B. & 61,9 & 62 & 1 & 14 & I,7 & 0,72 & 44,57 & 39,5 \\
\hline \multirow[t]{2}{*}{19} & G.R. & 63 & 60 & 1,05 & 53,4 & 6,5 & 2,74 & 172,62 & 148 \\
\hline & G.R. & 54,9 & 60 & 0,92 & 64,7 & 7,9 & 3,33 & 182,82 & 156,7 \\
\hline \multirow[t]{2}{*}{20} & E.U. & 33,2 & 60 & 0,55 & 23 & 2,8 & 1,18 & 39,18 & 33,6 \\
\hline & E.U. & 35,2 & 60 & 0,59 & 36,1 & 4,4 & 1,87 & 65,82 & 76,8 \\
\hline \multirow[t]{3}{*}{21} & A.L. & 82,9 & 70 & 1,18 & 7,5 & 0,9 & 0,38 & 31,5 & 31,5 \\
\hline & A.L. & 44,3 & 70 & 0,63 & 7,5 & 0,9 & 0,38 & 16,83 & 16,8 \\
\hline & A.L. & $4 I, I$ & 70 & 0,59 & 7,5 & 0,9 & 0,38 & 15,62 & 15,6 \\
\hline mean & & 55 & 70 & 0,78 & 31 & 3,7 & 1,6 & 83 & 85 \\
\hline s.d. & & 17 & 12 & 0,23 & 18 & 2,2 & 0,9 & 55 & 56 \\
\hline
\end{tabular}

Res. Time - Residence Time BMD - Bone Marrow Dose TBMD - Total Bone Marrow Dose TBMD/w - Total Bone Marrow Dose/weight

the increase in the remaining period of seven weeks. All variations found were values within the normal range, except in the two patients already described. No significant deviation was detected in the red blood cells parameter.

We found that patients with low hematocrit had high protein binding. This phenomenon was also reported previously for ${ }^{186}$ Re-HEDP, and was attributed to a possible in vivo decomposition leading to compounds having a different plasma protein binding [22]. Absorbed dose estimations for bone marrow were similar to those reported by Maxon et al (40) for both groups as it is shown in Table 7. 
Table 6: Evaluation of response to ${ }^{188}$ Re-HEDP treatment $(n=$ 18), compared to the status before dose administration.

\begin{tabular}{cccc}
\hline & Pain relief & Analgesic intake & Opiate intake \\
\hline & & & \\
Decrease & $78 \%$ & $62 \%$ & $100 \%$ \\
Increase & $11 \%$ & $17 \%$ & $0 \%$ \\
No change & $11 \%$ & $5 \%$ & $0 \%$ \\
\hline
\end{tabular}

* $33 \%$ abandoned opiate intake

Table 7: Estimated bone marrow absorbed doses for therapeutic bone radiopharmaceuticals $[5,4 I]$.

$(\mathrm{rad} / \mathrm{mCi}) \quad(\mathrm{mGy} / \mathrm{MBq})$

\begin{tabular}{lcc}
\hline${ }^{32 \mathrm{P}}$ & 14 & 3.8 \\
${ }^{89} \mathrm{Sr}$ & 50 & 13.5 \\
${ }^{153} \mathrm{Sm}$-EDTMP & 6 & 1.6 \\
186Re-HEDP & 3 & 0.8 \\
$188 \mathrm{Re}-H E D P$ & 2 & 0.5
\end{tabular}

Patients evaluated for PSA (free and total) and Tn are not statiscally conclusive due to the low number of cases. Nevertheless we consider important to evaluate these markers since the beginning of radiopharmaceutical therapy. In our observation there was an association between increased level of tumour markers and the onset of analgesic and pain as well as impaired physical activity.

Pain decrease was observed in $81 \%$ of the patients after administration of the therapeutic dose. In a $16.6 \%$ of these cases, relief was total. In the rest of the patients overall relief was approximately half (54\%) of the initial score of pain. Seventy five per cent of patients belonging to Group I started the pain relief between the first and second week after dose administration, maintaining this effect until 3 to 6 weeks. Patients from Group II showed an earlier response to treatment, reducing the pain during the first week post-injection with a longer duration of the response up to 16 weeks in one case. Our results are in accordance to those reported by Palmedo et al (40), even though higher pain palliation response was obtained in our case for both levels of activity administered.

\section{Conclusion}

We can conclude that ${ }^{188}$ Re-HEDP can be safely administered in the conditions of the above described protocol. Being bone marrow the critical organ for absorbed dose, estimated values were similar to those reported for other bone therapeutic radiopharmaceuticals in clinical use. The first administered dose (at tracer level) has an important role for evaluation of bone uptake and estimation of bone marrow absorbed dose in order to individualise the whole therapeutic scheme for each patient.

Residence times was an important parameter evaluated through urinary elimination of the radiopharmaceutical. Although the second group of patients $(2.2 \mathrm{GBq})$ received double administered activity, absorbed doses were highly dependent of bone uptake percentage. Seventy eight per cent of the patients reported an improved quality of life in terms of pain relief, reduction of analgesic intake and/or daily activity.

This study involved a small population, which does not allow detection of significant differences regarding pain relief degree and duration in different administered activities or multiple vs single doses, because of sample number. Nevertheless, it is a clear conclusion that higher level of administered dose or multiple doses were safe and well tolerated according to tested protocol.

\section{List of abbreviations used}

188Re-HEDP 188 Re-hydroxyethylidene diphosphate

PSA prostatic specific antigen

153Sm-EDTMP etylendiaminetetramethylenephosphonic acid

PAP prostatic acid phosphatase

DPD deoxypyrrolidine

TCA trichloroacetic

IRMA immnunoradiometric assay

I.D. injected dose

\section{Competing interests}

None declared

\section{Acknowledgements}

To Marta Sosa for her important collaboration in patients care during 188Re-HEDP administrations. This study was partially supported by the "Comisión Honoraria de Lucha contra el Cáncer" (CHLCC), IAEA RC 9823/RB and IAEA I0497/RO.

\section{References}

I. Volkert WA, Simon J, Ketring AR, Holmes RA, Lattimer LC, Corwing LA: Radiolabeled Phosphonic Acid Chelates: Potential Therapeutic Agents for Treatment of Skeletal Metastates. Drugs of the Future 1989, 8 (14):799-8I|

2. Robinson RG: Systemic Radioisotopic Therapy of Primary and Metastatic Bone Cancer. J. Nuc. Med 1990, 31:1326-1327 
3. Campa JA III, Payne R: The management of intractable bone pain : a clinician's perspective. Sem. Nuc. Med I992, I (XXII):310

4. Lewington VJ: Targeted Radionuclide Therapy for Bone Metastases. Eur. J. Nuc. Med 1993, 20:66-74

5. Davis LP, Porter AT: Systemic Radionuclide Therapy. Nuclear Medicine's Role in the Palliation of Painful Bone Metastases. In: Nuc. Med. Annual (Edited by Freeman L M) Raven Press; New York; 1995169-185

6. Silberstein E, Taylor A Jr: Procedure Guideline for Bone Pain Treatment: I.0. J. Nuc. Med, 1996, 37(5):88I-884

7. Silberstein E, Elgazzar A, Kapilivsky A: Phosphorus-32 : adiopharmaceuticals for the Treatment of Painful Osseous Metastases. Sem. Nuc. Med 1992, I (XXII): I7-27

8. Poter AT, McEwan AJB, Poew JE, et al: Results of a Randomized Phase-III Trial to Evaluate the Efficacy of Strontium-89 Adjuvant to Local Field External Beam Irradiation in the Management of Endocrine Resistant Metastatic Prostate Cancer. Int. J. Radiation Oncology Biol. Phis 1993, 25:805-8I3

9. Robinson RG, Preston DF, Spicer JA, Baxter KG: Radionuclide Therapy of Intractable Bone Pain: Emphasis on Strontium89. Sem. in Nuc. Med I992, I (XXII):28-32

10. Ketring AR: I53Sm-EDTMP and I86Re-HEDP as Bone Therapeutic Radio-pharmaceuticals. Nucl. Med. Biol I987, 3 (I 4):223232

II. Maxon HR, Schroder LE, et al: Re-I86 (Sn) HEDP for Treatment of Painful Osseous Metastases: Initial Clinical Experience in 20 Patients with Hormone-Resistant Prostate Cancer. Radiology 1990, I76:155-159

12. Maxon HR, Schroder LE, et al: Rhenium-I86 (Sn) HEDP for Treatment of Painful Osseous Metastases: Results of a Double-blind Crossover Comparison with Placebo. J. Nuc. Med 1991, 32:1077-1881

13. de Klerk JMH, Van Kijk A, et al: Pharmacokinetics of RheniumI 86 After Administration of Rhenium- I 86-HEDP to Patients with Bone Metastases. J. Nuc. Med 1992, 33:646-65I

14. Goeckeler WF, Edwards B, et al: Skeletal Localization of Samarium- 53 Chelates: Potential Therapeutic Bone Agents. J. Nuc. Med 1987, 28:495-504

15. Holmes R: I53Sm-EDTMP: A Potential Therapy for Bone Cancer Pain. Sem. in Nuc. Med 1992, 22:41-45

16. Eary JF, Collins C, et al: Samarium-I53-ETMP Biodistribution and Dosimetric Estimation. J. Nuc. Med 1993, 34:1031-1036

17. Logan KW, Volkert WA, Holmes RA: Radiation Dose Calculations in Persons Receiving Injection of Samarium-I53 EDTMP. J. Nuc. Med 1987, 4(28):505-509

18. Maxon HR, Deutsch EA, et al: Re-I86 (Sn)-HEDP for Treatment of Multiple Metastatic Foci in Bone: Human Biodistribution and Dosimetric Studies. Radiology 1988, I 66:501-507

19. Heggie JCP: Radiation Absorbed Dose Calculations for Samarium-I53-EDTMP Localized in Bone. J. Nuc. Med 1991, 5 (32):840-844

20. de Klerk JMH, van het Schip AD, Zonnenberg BA, et al: Evaluation of Thrombocytopenia in Patients Treated with RheniumI 86-HEDP: Guidelines for individual dosage recommendations. J. Nuc. Med 1994, 35:|423-|428

21. de Klerk JMH, van Dieren EB, et al: Bone Marrow Absorbed Dose of Rhenium- I86-HEDP and the Relationship with Decreased Platelet Counts. J. Nuc. Med 1996, 37:38-4 I

22. van Rijk PP, de Klerk JMH, Zonnenberg BA, et al: Pain Palliation Using Rhenium- I 86-Etidronate in Patients with Bone Metastases. Proceed. of the Fourth International Symposium on Technetium in Chemistry and Nuclear Medicine. In: Technetium and Rhenium in Chemistry and Nuclear Medicine, $N^{\circ} 4$. (Edited by: Nicolini M, Bandoli G, Mazzi U.); Padova, SG Editoriali ; 1995527-534

23. Callahan AP, Rice DE, Knapp FF Jr: Rhenium- I 88 for Therapeutic Applications from an Alumina-based Tungsten- I88/Rhenium- I 88 Radionuclide Generator. Nuc. Compact I 989, 20:3-6

24. Kamioki H, Mirzadeh S, Lambrecht RM, Knapp FF Jr, Dadachova K: I 88W/I88Re Generator for Biomedical Applications. Radiochimica Acta 1994, 65:39-46

25. Knapp FF Jr, Mirzadeh S, Beets AL, O'Doherty M, Blower PJ, Verdera ES, Gaudiano JP, Kropp J, Guhlke H, Palmedo H, Biersack HJ: Reactor-produced radioisotopes from ORNL for bone pain palliation. Appl. Radiat. Isot 1998, 49:309-3I5
26. Volkert WA, Goeckeler WF, Ehrhardt GJ, Ketring AR: Therapeutic radionuclides: production and decay property considerations. J. Nuc Med 1991, 32:174-185

27. Quirijnen J, Han SH, Zonnenberg BA, de Klerk JMH, van het Schip $A D$, van Dijk A, ten Kroode HFJ, Blijham GH, van Rijk PP: Efficacy of Rhenium-186-Etidronate in prostate cancer patients with metastatic bone pain. J. Nuc. Med 1996, 37:151।-1515

28. Hakomori S: Aberrant glycosylation in tumors and tumor-associated carbohydrate antigens. Adv. Cancer Res 1989, 52:257331

29. Fukuda M: Possible roles of tumor-associated carbohydrate antigens. Cancer Res 1996, 56:2237-2244

30. Muramatsu T: Carbohydrate signals in metastasis and prognosis of human carcinomas. Glycobiology 1993, 3:291-296

31. Osinaga E, Pancino G, Porchet N, Mistro D, Aubert JP, Roseto A: Analysis of the carcinoma-associated epitope defined by monoclonal antibody 83D4. J. Tumor Marker Oncol 1992, 7:13-24

32. Charpin C, Pancino G, Osinaga E, Bonnier P, Lavaut MN, Allasia C, Roseto A: Monoclonal antibody 83D4 immunoreactivity in human tissues: cellular distribution, and microcytophotometric analysis of immunoprecipitates on tissue sections. Anticancer Research 1992, I 2:209-224

33. Corey E, Wegner S, Corey M, Vessella Robert: Prostate Specific Antigen: Characterization of epitopes by synthetic peptide mapping and inhibition studies. Clin. Chem I997, 43(4):575-584

34. Fagiolino $P$, Savio E, Stareczek S: Linear relationships in systems with non linear kinetics. Eur. J. of Biopharm. and Pharmacokin. Special Issue 199039

35. Loevinger R, Budinger TF, Watson EE: MIRD Primer for Absorbed Dose Calculations. New York of Nuclear Medicine, 1988

36. Verdera ES, Gaudiano J, León A, Martínez G, Robles A, Savio E, León E, Mc Pherson DW, Knapp FF Jr: Radiochimica Acta I 997, 2 I 9: I-5

37. Gibaldi M, Perrier D: In: "Pharmacokinetics". Marcel Dekker, 1975

38. Robles AM, Balter HS, Oliver P, Welling M, Pawels EKJ: Improved radioiodination of biomelecules using exhaustive Cloramine T oxidation. Nuc. Med. Biol, $200 \mathrm{I}$

39. Subramanian G, Mc Afee JC, Blair Rj, Kallfelz HS, Thomas FD: Technetium-99m-methylene diphosphate - a superior agent for skeletal imaging: comparison with other tecnetium complexes. J. Nucl Med 1975, I6(8):744-755

40. Maxon HR III, et al: Rhenium-I88(Sn) HEDP for treatment of Osseus Metastases. J. Nuc Med 1998, 39(4):659-663

4I. Palmedo H, Guhlke S, Bender H, Sartor J, Schoeneich G, Risse J, Grünwald F, Knapp FF Jr, Biersack HJ: Dose escalation study with Rhenium- I 88-hydroxy-ethylidene diphosphonate in prostate cancer patients with osseous metastases. Eur. Nuc. Med 2000, 27:123-130

Publish with BioMed Central and every scientist can read your work free of charge

"BioMedcentral will be the most significant development for disseminating the results of biomedical research in our lifetime." Paul Nurse, Director-General, Imperial Cancer Research Fund

Publish with BMC and your research papers will be:

- available free of charge to the entire biomedical community

- peer reviewed and published immediately upon acceptance

- cited in PubMed and archived on PubMed Central

- yours - you keep the copyright

Submit your manuscript here:

http://www.biomedcentral.com/manuscript/ 